\title{
Synthesis and Structural Characterization of $\operatorname{Bis}\left(\mu_{2}\right.$-Iodo)- Bis(Diethyl Ether)-( $N-N^{\prime}$-(Bis(2,6-Diisopropylphenyl)Pentane-2,4- Diketiminato)-Lithium-Chromium, a $\mathrm{Cr}$ (II) ( $\beta$-Diketiminato) Complex with a Coordinated LiI Salt
}

Wesley H. Monillas · Glenn P. A. Yap •

Klaus H. Theopold

Published online: 31 March 2009

(C) Springer Science+Business Media, LLC 2009

Erratum to: J Chem Crystallogr (2009) 39:377-379

DOI 10.1007/s10870-009-9516-1

The first sentence under the Results and Discussion section on page 378 is corrected as follows:

A search of the Cambridge Structural Database [16] shows 11 structurally characterized complexes of the general form $\mathrm{LM}(\mu-\mathrm{X})_{2} \operatorname{Li}(\text { solv })_{2}$, where $\mathrm{L}=N$ - $N^{\prime}$-bis(2,6diisopropylphenyl)pentane-2,4-diketiminato or 'nacnac', $\mathrm{M}=$ any metal, $\mathrm{X}=$ halide, and solv = either tetrahydrofuran or diethylether [4, 17-22].

In addition, reference 16 is updated as follows:

Allen FH (2002) Acta Cryst B58:380.

The online version of the original article can be found under doi: 10.1007/s10870-009-9516-1. 